\section{Obesity and Weight Concerns in Children with Special Needs in a Developing Country}

Prithiviraj Bahadursingh ${ }^{1}$, Vijaya Siew ${ }^{1}$, Meera Maharaj ${ }^{1}$, Chardae Legall $^{1}$, Sitara Bachan ${ }^{1}$

${ }^{1}$ South-West Regional Health Authority, San Fernando, Trinidad and Tobago

\section{Corresponding Author:}

Prithiviraj Bahadursingh

Consultant Community Paediatrician

South-West Regional Health Authority

San Fernando

pbahadursingh@swrha.co.tt

\section{DOI: $\underline{\text { doi.org/10.48107/2021.04.010 }}$}

Copyright: This is an open-access article under the terms of the Creative Commons Attribution License which permits use, distribution, and reproduction in any medium, provided the original work is properly cited.

(C)2021 The Authors. Caribbean Medical Journal published by Trinidad \& Tobago Medical Association

\section{ABSTRACT}

\section{Objective}

To investigate weight concerns in children with special needs.

\section{Methods}

Data from an established patient database on Microsoft Excel for a local community paediatric service was analysed for September 2015 to August 2016. Patient diagnoses were categorised as follows: Attention Deficit and Hyperactivity Disorder (ADHD), Autism Spectrum Disorder (ASD), Learning Difficulty (LD), Cerebral Palsy (CP), Global Developmental Delay (GDD), Trisomy 21 ( $T$ 21) and Other syndromes. The proportions of these children being overweight/obese, underweight, having eating problems, requiring dietician services and having behavioural problems were recorded. Odds ratios were calculated comparing subgroups.

\section{Results}

One thousand and seventeen (1017) patients attended the clinics; Seven hundred and seventy one (771) were male. Fifteen point four percent $(15.4 \%, 157)$ of patients had weight concerns, with $9.3 \%$ (95) being overweight or obese and $6.1 \%$ (62) underweight. Five point one percent $(5.1 \%, 52)$ of children experienced eating problems. Seven point nine percent $(7.9 \%, 80)$ patients accessed the dietician services and behavioral concerns were noted in $8.8 \%$ (90) patients. Regarding ASD, the odds of being overweight or obese was lower compared to the rest of the group; 3.7\% (15) were overweight or obese. For ADHD, 15\% (13) were overweight or obese. Amongst children with Learning Difficulty, $17.5 \%$ (44) were overweight or obese. CP children had higher odds of being underweight compared to the rest of the group (14.9\% of children with CP were underweight). For Trisomy 21 and other syndromes, 17\% (5) were overweight or obese.

\section{Conclusion}

International data indicates that children with special needs have high rates of overweight and obesity. This study also shows that a significant proportion of children with special needs are overweight or obese and at risk of Non-Communicable Diseases (NCDs) like cardiovascular 
disease and diabetes. Strategies implemented locally to address NCDs must give emphasis to children with special needs.

Keywords: Obesity, Special Needs, Children

\section{INTRODUCTION}

According to the World Health Organization (WHO), there were nearly 41 million children under five years old who were considered overweight or obese in $2016 .{ }^{1}$

Additionally, a recent study, led by the Imperial College London and the WHO, published in The Lancet in October 2017 , notes that the number of obese children and adolescents (aged five to nineteen years) worldwide has risen tenfold in the past four (4) decades. ${ }^{2}$ The Centers for Disease Control and Prevention (CDC) in the United States of America (USA) stated that the prevalence of obesity is $17 \%$ and 12.7 million children and adolescents in the USA are affected. ${ }^{3}$

In Trinidad and Tobago, a cross-sectional study to determine the prevalence of obesity and other risk factors for type 2 diabetes among school children in Trinidad, showed that $15 \%$ of children were obese and $17 \%$ were overweight. $^{4}$

The CDC (USA) noted that $20 \%$ of children aged 10 to 17 with special needs are obese compared with $15 \%$ of children of the same ages without special needs. ${ }^{5}$ Currently, there is no data regarding obesity and overweight in children with special needs in Trinidad and Tobago. The World Health Organization (WHO) states that NCDs are chronic diseases of "long duration which are the result of a combination of genetic, physiological, environmental, and behavioral factors"; the main types of NCDs are cardiovascular disease, cancers, chronic respiratory disease and diabetes. ${ }^{6}$ Obesity is a significant risk factor for NCDs like diabetes and cardiovascular disease and would impact the long-term quality of life of children with special needs if they develop these conditions.

The National Strategic Plan for the Prevention and Control of Non-Communicable Diseases: Trinidad and Tobago 2017-2021 sates, "...ultimately, the high level of overweight and obesity beginning from childhood and continuing into adulthood further contributes to the overall increased risk of NCDs in the population." The plan broadly addresses childhood obesity; it highlights the social determinants of health and the need for multisectoral collaboration, equity, a human rights and culturally-sensitive approach, but it does not address specifically the child with special needs. ${ }^{7}$

This study aims to show the necessity for increased focus of public health on obesity, especially with regards to children with special needs.

\section{METHODOLOGY}

Five (5) specialty community paediatric clinics exist within the South-West Regional Health Authority (SWRHA) of Trinidad and Tobago. Morbidity data is collected on an ongoing basis using a Microsoft Excel spreadsheet. Data from September 2015 to August 2016 was analysed using an Excel spreadsheet. Odds ratios were also utilized to analyse subgroups within our sample; a P- Value of $\mathrm{P}<$ 0.05 was considered statistically significant.

The patients were grouped based on their diagnosis as follows: Attention Deficit and Hyperactivity Disorder (ADHD), Autism Spectrum Disorder (ASD), Learning difficulty (LD), Cerebral Palsy (CP), Global Developmental Delay (GDD), Trisomy 21 and Other Syndromes. The Merriam-Webster dictionary definition of "special needs" was utilised for the purpose of this study: "Special needs refer to any of various difficulties (such as physical, emotional, behavioral, or learning disability or impairment) that causes an individual to require additional or specialized services or accommodations (such as in education or recreation)."

Growth parameters were assessed using the WHO growth standards. ${ }^{8}$ For children less than five years, Overweight was defined as a BMI Z-score between +2 to +3 , and Obesity, a BMI Z-score of more than $Z+3$. For children more than five years, Overweight was defined as a BMI $Z$ -score between $Z+1$ to +2 , and Obesity a BMI Z-score of more than +2 . Underweight was defined as a BMI $Z$ score between $Z-2$ and $Z-3$, and Severely Underweight, a BMI Z- score of less than $Z-3$.

Morbidity data collected included being obese/overweight, underweight, having behavioural problems and eating problems. Information on access to the social welfare 
grants, special school placement, dietician and child protection concerns were also recorded.

\section{RESULTS}

There were 1362 patient visits with 314 new patient visits and 1048 scheduled review visits. A total of 1017 patients attended the clinics as detailed in Table 1 below. Patients' ages ranged from 1 to 22 years old. 771 patients were male. There was a higher proportion of males in each diagnostic group; in the ADHD, ASD and CP groups more than $75 \%$ of patients were male. $48 \%$ (488) of patients were in the 5 to 10 years age group.
ASD had the highest prevalence within the clinic at $39.8 \%$ (405) with learning difficulty (24.7\%) (252) being the second most common diagnosis as illustrated in Table 2 below. ADHD had an $8.5 \%$ (86) prevalence rate.

Behavioural issues were recorded in 9\% (90) of the study population ( $\mathrm{N}=1017) ; 22 \%$ (19) of $\mathrm{ADHD}, 9.6 \%$ (39) of ASD and $7.1 \%$ (18) of LD. The odds of behavioural problems were higher in the ADHD group compared to the rest of the group (OR 3.4; 95\% CI 1.9-6.3; $\mathrm{P}=0.0001$ ).

Table 1. Age and Gender Distribution in Diagnostic groups.

\begin{tabular}{|l|l|l|l|l|l|l|l|}
\hline Diagnosis & $\begin{array}{l}\mathbf{0 - 5 y r s} \\
\text { Male }\end{array}$ & $\begin{array}{l}\mathbf{0 - 5 y r s} \\
\text { Female }\end{array}$ & $\begin{array}{l}\mathbf{5 - 1 0 y r s} \\
\text { Male }\end{array}$ & $\begin{array}{l}\mathbf{5 - 1 0 y r s} \\
\text { Female }\end{array}$ & $\begin{array}{l}\mathbf{> 1 0 y r s} \\
\text { Male }\end{array}$ & $\begin{array}{l}\mathbf{> 1 0} \text { yrs } \\
\text { Female }\end{array}$ & Total \\
\hline ADHD & 4 & 2 & 48 & 8 & 22 & 2 & 86 \\
\hline ASD & 121 & 26 & 146 & 41 & 60 & 11 & 405 \\
\hline CP & 30 & 6 & 17 & 6 & 12 & 3 & 74 \\
\hline LD & 10 & 13 & 85 & 47 & 66 & 31 & 252 \\
\hline GDD & 58 & 15 & 51 & 24 & 21 & 2 & 171 \\
\hline T 21 & 2 & 0 & 4 & 5 & 0 & 0 & 11 \\
\hline $\begin{array}{l}\text { Other syn- } \\
\text { dromes }\end{array}$ & 3 & 5 & 5 & 1 & 2 & 2 & 18 \\
\hline Total & $\begin{array}{l}228 \\
(2.4 \%)\end{array}$ & $\begin{array}{l}(6.6 \%) \\
(35 \%)\end{array}$ & $\begin{array}{l}356 \\
(13 \%)\end{array}$ & $\begin{array}{l}183 \\
(18 \%)\end{array}$ & $\begin{array}{l}51 \\
(5 \%)\end{array}$ & 1017 \\
\hline
\end{tabular}


Table 2. Diagnostic Groups and various morbidities.

\begin{tabular}{|l|l|l|l|l|l|l|l|l|l|}
\hline $\begin{array}{l}\text { Diag- } \\
\text { nostic } \\
\text { Group }\end{array}$ & Total & $\begin{array}{l}\text { Over- } \\
\text { weight }\end{array}$ & $\begin{array}{l}\text { Under- } \\
\text { weight }\end{array}$ & $\begin{array}{l}\text { Eating } \\
\text { prob- } \\
\text { lems }\end{array}$ & $\begin{array}{l}\text { Behav- } \\
\text { ior } \\
\text { con- } \\
\text { cerns }\end{array}$ & $\begin{array}{l}\text { Dieti- } \\
\text { cian }\end{array}$ & $\begin{array}{l}\text { Child } \\
\text { protec- } \\
\text { tion } \\
\text { con- } \\
\text { cerns }\end{array}$ & $\begin{array}{l}\text { Wel- } \\
\text { fare } \\
\text { grant }\end{array}$ & $\begin{array}{l}\text { Special } \\
\text { school } \\
\text { place- } \\
\text { ment }\end{array}$ \\
\hline ADHD & 86 & 13 & 4 & 3 & 19 & 11 & 1 & 27 & 9 \\
\hline ASD & 405 & 15 & 14 & 29 & 39 & 26 & 2 & 131 & 65 \\
\hline CP & 74 & 2 & 11 & 0 & 0 & 8 & 0 & 39 & 12 \\
\hline LD & 252 & 44 & 9 & 8 & 18 & 17 & 1 & 85 & 66 \\
\hline GDD & 171 & 16 & 21 & 12 & 12 & 18 & 2 & 111 & 46 \\
\hline T 21 & 11 & 2 & 1 & 0 & 0 & 0 & 1 & 8 & 11 \\
\hline $\begin{array}{l}\text { Other } \\
\text { syn- } \\
\text { dromes }\end{array}$ & 18 & 3 & 2 & 0 & 2 & 0 & 1 & 7 & 2 \\
\hline
\end{tabular}

ASD had the highest prevalence within the clinic at $39.8 \%$ (405) with learning difficulty (24.7\%) (252) being the second most common diagnosis as illustrated in Table 2 below. ADHD had an $8.5 \%$ (86) prevalence rate.

Behavioural issues were recorded in 9\% (90) of the study population ( $\mathrm{N}=1017) ; 22 \%$ (19) of $\mathrm{ADHD}, 9.6 \%$ (39) of ASD and $7.1 \%$ (18) of LD. The odds of behavioural problems were higher in the ADHD group compared to the rest of the group (OR 3.4; 95\% CI 1.9-6.3; $\mathrm{P}=0.0001)$.

Of the 1017 patients, 157 (15.4\%) were noted to have weight concerns with $9.3 \%$ (95) of them being overweight or obese, and 6\% (62) of patients being underweight. Figure 2 shows the proportions of children who were overweight and underweight within each diagnostic group.

Children with learning difficulty had higher odds of being overweight compared to the rest of the group (OR 3; 95\% CI 1.9 to 4.6; P 0.0001). The likelihood of being overweight in Trisomy 21 and other syndromes compared to the rest of the group was higher but not statistically significant (OR 2; 95\% CI 0.7 to 5.5; P 0.14). Children with ADHD also had a higher likelihood of being overweight when compared to the rest of the group but was not statistically significant (OR $1.8 ; 95 \%$ CI 0.98 to 3.4; P 0.06). Nine point three (9.3\%) of children with GDD were overweight- this was similar to the rest of the group (OR $1 ; 95 \%$ CI 0.6 to 0.99 ).

Children with ASD had a lower likelihood to be overweight compared to the rest of the group (OR $0.25 ; 95 \%$ CI 0.14 to $0.4 ; \mathrm{P} 0.0001$ ). Children with Cerebral Palsy were more likely to be underweight compared to the rest of the sample (OR 3; 95\% CI 1.5 to 6.1; P 0.002). In ASD, the proportion of kids being overweight versus underweight was similar at 3.7\% (15) and 3.4\% (14) respectively. Children with ADHD, LD and Trisomy 21 were more likely to be overweight than underweight.

Eating problems were only recorded in 52 (5.1\%) children. This number is less than that of children who were underweight ( 62 or $6 \%$ of the sample) and overweight/obese (95 or $9.3 \%$ of the sample). It is likely that there were more eating problems than were actually recorded. The majority of patients with eating problems were in the ASD group (2.9\% (29) of the sample and $7.1 \%$ (29) of the ASD group). The odds ratio of eating problems in the ASD group compared to the rest of the 
Figure 1. Proportion of various diagnoses in the clinic.

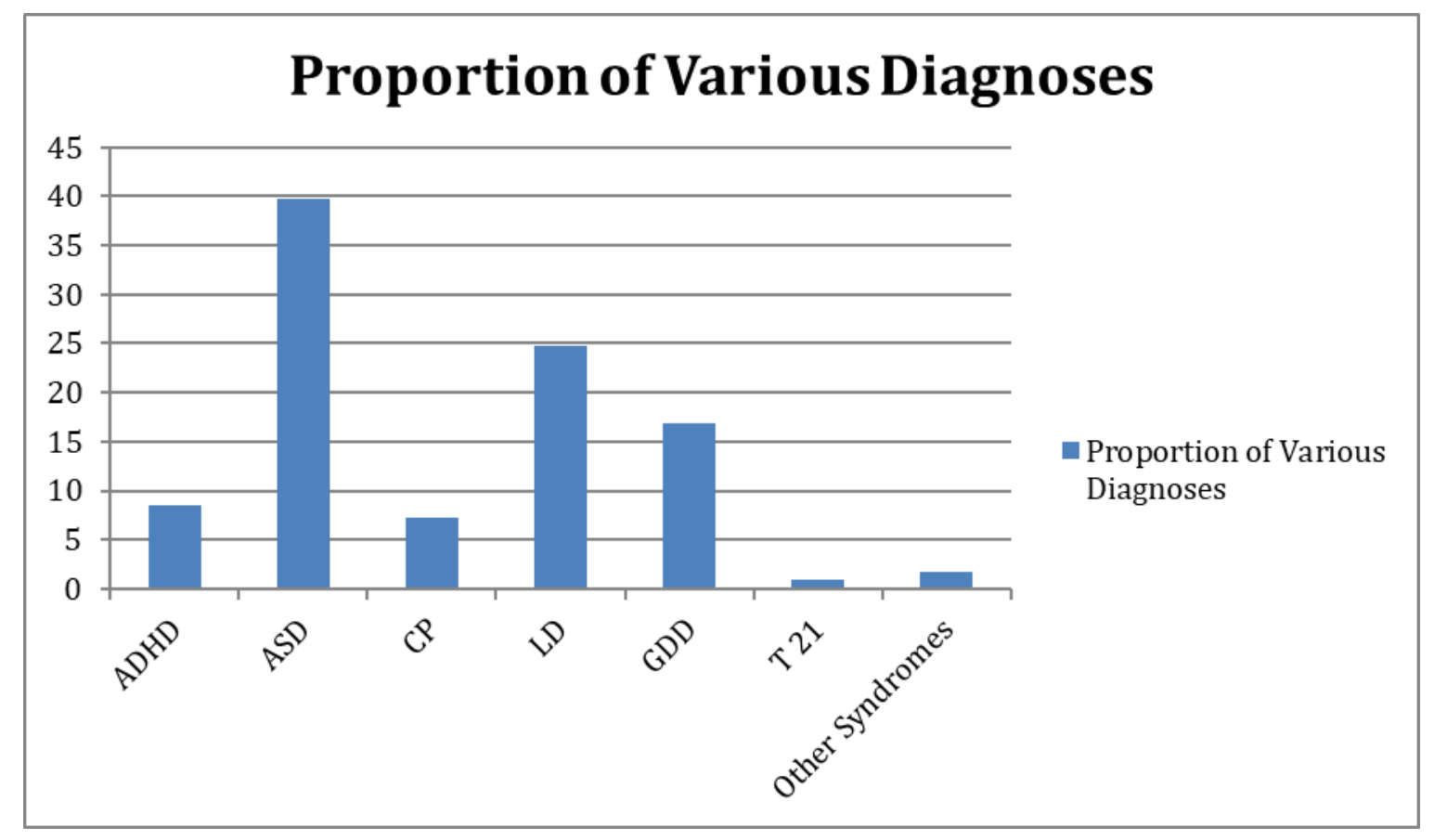

Figure 2. Proportion of Overweight/Obese and Underweight children based on diagnosis

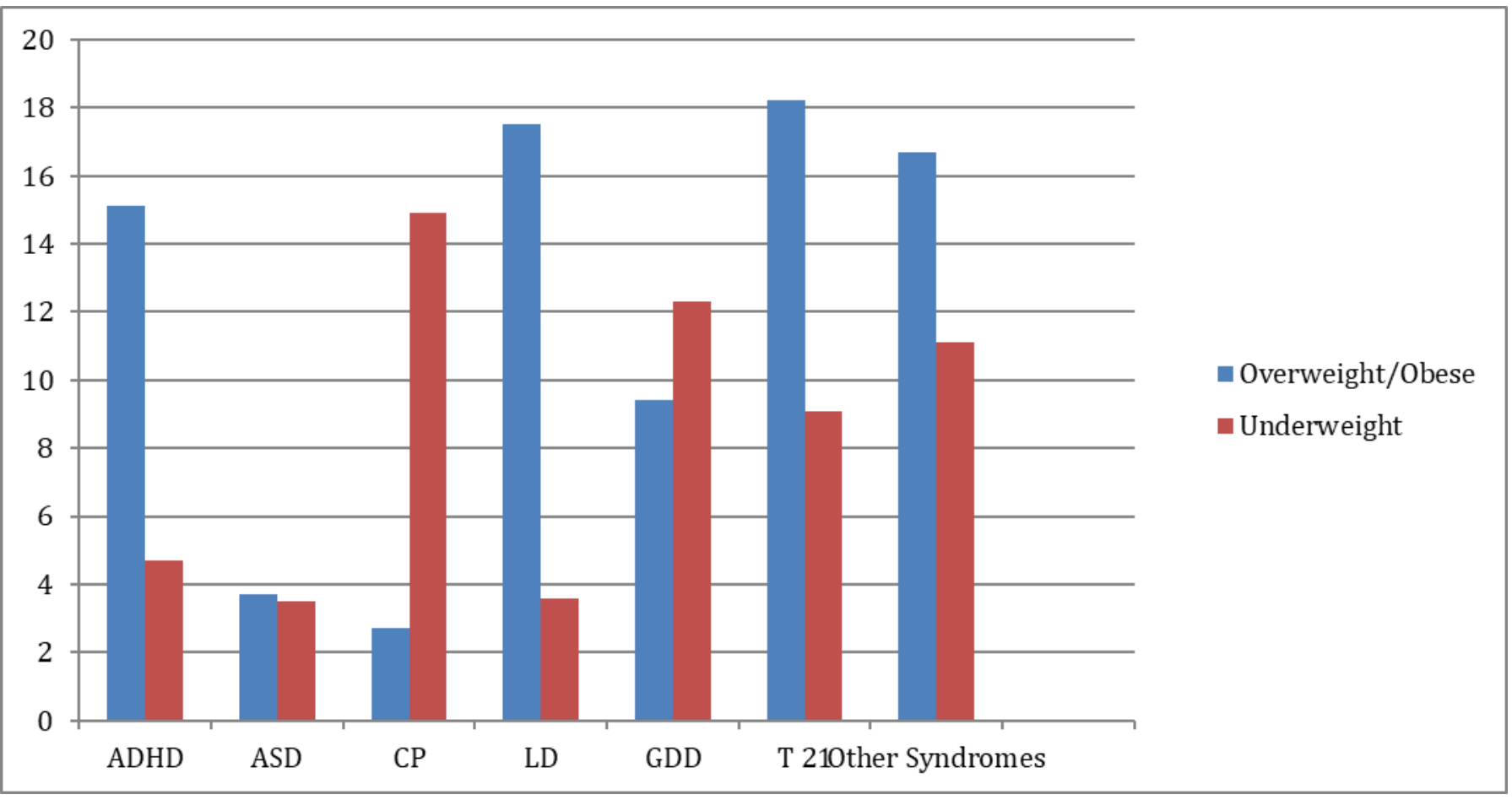


group was high (OR 1.97; 95\% CI 1.12 to 3.46; P 0.017). Of the children with ASD and eating problems, $90 \%$ accessed the dietician. Overall, $67 \%$ of the children with eating problems accessed the dietician.

Overall, $40 \%$ of children were receiving welfare support. Children with Cerebral Palsy had a higher likelihood to receive the welfare support compared to the rest of the group (OR 1.9; 95\% CI 1.2 to 3.1; P 0.006). In less than $1 \%$ of children, child protection concerns were noted. Twenty one percent $(21 \%)$ of children attended a special school.

\section{DISCUSSION}

Obesity can significantly impact quality of life due to the risk of NCDs, especially cardiovascular disease and diabetes. This impact is even greater when the persons have special needs. The CDC has recognised that children and adults with mobility limitations, intellectual or learning disabilities are at greatest risk for obesity; from the 2003-2008 National Health and Nutrition Examination Survey, obesity rates for children with disabilities were $38 \%$ higher than for children without disabilities. ${ }^{5}$

There is no recent data in Trinidad and Tobago on the exact number of children with special needs, developmental problems or disabilities in the paediatric population. In 1984, the Report of a National Survey of Handicapped Children and Youth in Trinidad and Tobago identified the estimated prevalence of children with special needs aged 3 to 16 years as being $16.1 \%$ of the population. A UNICEF Eastern Caribbean report stated that Trinidad and Tobago's 2000 Census reported $1.1 \%$ of children 0 to 18 years of age with a disability; ${ }^{9}$ this figure is very likely to be an underrepresentation since, currently, Autism Spectrum Disorder by itself may be at least $1 \%$ of the population. The CDC figures indicate that about $17 \%$ of children aged 3 to 17 years may have some form of a developmental disability. ${ }^{10}$

The Community Paediatric Service of the SWRHA is responsible for assessing and managing children who have developmental concerns; almost $90 \%$ of referrals are for developmental concerns. We looked at weight concerns in children attending the clinics but there was no well child comparison group. The proportions of children with overweight or obesity, however, were large in the various diagnostic categories but less when compared to the general population. ${ }^{4}$ Children with learning difficulty, ADHD, Down Syndrome, Global Developmental Delay and other syndromes all had high rates of obesity ranging from $9.4 \%$ to $18.7 \%$.

Interestingly, in the ASD group, which had the highest prevalence $(29.7 \%$ (405) and the highest rates of eating problems $(7.1 \%(29))$, the proportion of overweight or obesity was low at $3.7 \%$ (15). Underweight children with ASD were also low at 3.0\% (14). Hill et al in their article on Obesity and Autism indicated that overweight in children with autism was as high as $33.6 \%$ and obesity $18 \% .{ }^{11}$ A National Sample of US Adolescents with Autism and Other Learning and Behavioral Disorders showed that adolescents with autism were twice as likely to be obese compared to peers without disability; the study also showed that $31.8 \%$ of the children with autism were obese. ${ }^{12}$ Further research would be needed to understand why the rates detected in our sample were lower than international data. Ninety percent $(90 \%)$ of the ASD children with eating problems accessed the dietician; this may have had an impact on their weight parameters. Data regarding access to Occupational Therapy for eating concerns was not determined. This is an area where further research is required. Some children with ASD and eating problems in our sample may have had a normal BMI; further research would be needed to explore this issue.

A literature review by Bertapelli et al regarding obesity in children with Down Syndrome showed obesity rates ranging from $23 \%$ to $70 \% .{ }^{13}$ In our study, $18.7 \%$ of children with Down Syndrome were overweight. Children with cerebral palsy in our sample were more likely to be underweight. We did not collect data regarding whether the children were ambulatory or non-ambulatory. Hurvitz et al showed that ambulatory patients with cerebral palsy were more likely to be obese than non-ambulatory patients. ${ }^{14}$ In a Norweigan study, Dahlseng et al showed that children with cerebral palsy who had gastrostomy tubes for longer had higher BMIs. ${ }^{15}$ In our sample, none of the children had gastrostomy tubes-this may be a possible reason for the higher rates of underweight.

A National Sample of US Adolescents with Autism and Other Learning and Behavioural Disorders showed that the percentage of obesity in adolescents with ADHD was 
$17.6 \%$ and $19.8 \%$ for adolescents with Intellectual disability. ${ }^{12}$ Our study showed that $15 \%$ (13) of children with ADHD and $17.4 \%$ (44) with LD were overweight or obese. Children with Learning difficulty comprised the second largest group in our review (18.5\% (252)) and these children were more likely to be overweight compared to the rest of the sample.

Other factors which may contribute to obesity in children with special needs but not addressed in this study include physical constraints, lack of accessible environments to exercise, challenges with chewing or swallowing food, medications which can contribute to weight gain and sleep problems.

\section{CONCLUSION}

Our study shows that children with special needs have a significant risk for childhood obesity. The complications of obesity would undoubtedly affect quality of life since they would be at risk of NCDs like cardiovascular disease and diabetes. National policy regarding non-communicable disease and obesity should give particular attention to children with special needs.

Ethical Approval statement: Ethical approval was obtained from the South-West Regional Health Authority Bioethics Committee

Conflict of interest statement: None declared

Informed Consent statement: Not applicable

Funding statement: None

Authors Contribution: Data collection, analysis and write-up: Prithiviraj Bahadursingh, Vijaya Siew, Meera Maharaj, Chardae Legall, Sitara Bachan.

\section{REFERENCES}

1. World Health Organization. Obesity and Overweight. [Internet]. Jun 2018. [cited $12^{\text {th }}$ Jun 2018]. http:// www.who.int/news-room/fact-sheets/detail/obesityand-overweight

2. World Health Organization. News: Tenfold increase in childhood and adolescent obesity in four decades: new study by Imperial College London and WHO.
[Internet]. Jun 2018. [cited $12^{\text {th }}$ Jun 2018]. Available from: http://www.who.int/news-room/detail/11-102017-tenfold-increase-in-childhood-and-adolescentobesity-in-four-decades-new-study-by-imperialcollege-london-and-who

3. CDC. Overweight and Obesity. [Internet]. June 2018. [cited $12^{\text {th }}$ Jun 2018]. Available from: https:// www.cdc.gov/obesity/data/childhood.html

4. Batson YA, Teelucksingh S, Maharaj RG, et al. A cross -sectional study to determine the prevalence of obesity and other risk factors for type 2 diabetes among school children in Trinidad, West Indies. Paediatrics and International Child Health 2014; Volume 34 (3): 178-183

5. CDC. Disability and Obesity. [Internet]. Jun 2018. [cited $12^{\text {th }}$ Jun 2018]. Available from: https:// www.cdc.gov/ncbddd/disabilityandhealth/obesity.html

6. World Health Organization. Non communicable diseases. [Internet]. July 2020 [cited $13^{\text {th }}$ July 2020]. Available from: https://www.who.int/news-room/factsheets/detail/noncommunicable-diseases

7. National Strategic Plan for the Prevention and Control of Non Communicable Diseases: Trinidad and Tobago 2017 - 2021 Working Together to Build a Healthy and Happy Nation. [Internet]. Jun 2018. [cited $12^{\text {th }}$ Jun 2018]. Available from: http://www.health.gov.tt/ncd/

8. World Health Organization. Child Growth Standards. [Internet]. [cited $24^{\text {th }}$ June 2020]. Available from: https://www.who.int/childgrowth/standards/en/

9. Unicef State of the World's Children, Eastern Caribbean Area Supplement. [Internet]. Jun 2018. [cited Jun 2018]. Available from: https:// www.unicef.org/easterncaribbean/ EC_SOWCR_2013_SM.pdf

10. CDC. Developmental Disabilities. [Internet]. June 2018. [cited $12^{\text {th }}$ Jun 2018]. Available from: https:// www.cdc.gov/ncbddd/developmentaldisabilities/ facts.html

11. Hill AP, Zuckerman KE, Fombonne E. Obesity and Autism. PEDIATRICS 2015;Volume 136 (6): 10511061

12. Phillips KL, Schieve LA, Visser S, et al. Prevalence and 
Impact of Unhealthy Weight in a National Sample of US Adolescents with Autism and Other Learning and Behavioral Disabilities. Maternal and Child Health Journal. 2014 Oct; 18(8): 1964-1975.

13. Bertapelli F, Pitetti K, Agiovlasitis S, et al. Overweight and obesity in children and adolescents with Down syndrome-prevalence, determinants, consequences, and interventions: A literature review. Research in Developmental Disabilities. 2016 Oct; 57:181-92.

14. Hurvitz EA, Green LB, Hornyak JE, et al. Body Mass Index Measures in Children with Cerebral Palsy Related to Gross Motor Function Classification: A Clinic-Based Study. American Journal of Physical Medicine \& Rehabilitation 2008: Volume 87 (5): 395403

15. Dahlseng MO, Finbraten AK, Juliusson PB, et al. Feeding problems, growth and nutritional status in children with cerebral palsy. Acta Paediatrica 2012; Volume 101(1):92-8. 